\title{
MODELLING OIL SPILL AROUND BAY OF SAMSUN, TURKEY, WITH THE USE OF OILMAP AND ADIOS SOFTWARE SYSTEMS
}

\author{
Ali Cemal Toz \\ Dokuz Eylul University, Turkey
}

\begin{abstract}
Bay of Samsun is one of the most important oil transport gateways in Black Sea. The region is surrounded with the coasts which have various levels of environmental sensitivity. The purpose of this study is to investigate the oil spill and predict the future accidents likely to be encountered around the Bay of Samsun. To be well informed about fate, this study makes the best possible use of two trajectory models. One of them, ADIOS (Automated Data Inquiry for Oil Spills), has been applied to natural degradation calculations, and the other one, OILMAP (oil spill model and response system), has been used for surface spread simulation. Hence in order to identify the risky areas three scenarios have been developed. Their results reveal that in case of oil spills, with average environmental conditions, there is a risk of contamination for the city of Samsun. Although the area under the risk is the same, contamination density is totally different depending upon the quantity and the type of spilt oil. The results gained through these efforts are hoped to be useful for many organizations dealing with oil spill response operations and contribute to an effective coordination among the relevant institutions.
\end{abstract}

Keywords: trajectory; oil spill; Bay of Samsun ,Turkey; ADIOS; OILMAP; Black Sea; modelling

\section{INTRODUCTION}

When various types of oil get in contact with the water, numerous processes of physical and biological changes initiate suddenly. The processes have great effects on forms and behaviour of oil. The trajectory of oil in marine environment is directly related to several factors such as sea currents, winds, salinity, and oil type. $[15,12,30]$.

The main purpose of this study is to predict oil spill trajectory in spill incidents and thereby help in selecting priorities of oil spill response activities in Bay of Samsun. This study also aims to perform risk assessment for important resources in the affected region and to assist in developing coastal planning and management. Besides, modelling results of the study could be useful for guidance of decisions makers.

\section{MATHEMATICAL MODEL}

In this part a mathematical analysis defining weathering processes of oil is described. Short term processes are defined individually making use of available physical and environmental data (e.g. wind speed, temperature, oil composition etc.). Short term weathering processes are surface spread, evaporation and dispersion.

\section{SURFACE SPREAD}

This motion can be described as the movement of oil on the surface of water. The most commonly used spreading model has been developed by Fay [7]. In this process three phases involving dominant spreading and retarding forces are 
determined. The gravity-inertial spreading phase which lasts only few minutes is the first phase. Tension-viscous, the third phase, occurs when the slick may be dispersed. The second phase which is considered mainly by models, is known as the gravity-viscous spreading forces and formulated as follows [1]:

$$
D_{\text {Fay }}=\Delta_{\mathrm{p}-\mathrm{w}}\left(\frac{\Delta_{w} g \cdot V^{2}}{\sqrt{v_{w}}}\right)^{1 / 3} \cdot t^{-1 / 2}
$$

Here, $\Delta_{\mathrm{p}-\mathrm{w}}$ is the relative oil water density, $\mathrm{g}$ - gravitational acceleration, $\mathrm{V}$ - initial spill volume, $\mathrm{v}_{\mathrm{w}}$ - the kinematic viscosity of water, and $\mathrm{t}$ - the time after release. The second diffusion factor is defined to explain eddy diffusion of the surface water in addition to the first factor. Elliot and Hurford [6] conclude that such process is "non-Fickian" and a time dependent diffusion parameter better represents empirical results [19].

Shifting of oil due to the surface spread is mainly under the effects of winds and currents. The wind-based current speed is calculated equal to $3 \%(1 \%-6 \%)$ of wind velocity [24]. When both wind-based currents and tidal currents are present, the resultant movement can be calculated with the sum of two vector quantities [10]. Roughly two thirds of this movement represents Stokes drift of the surface waves. The remaining one third represents the movement of the slick along the water surface [19].

\section{EVAPORATION}

Evaporation is typically one of the most important weathering processes which start in short period just after spill. Evaporation is the main reason of the shifting of oil molecules from liquid phase to vapour phase. More volatile substances tend to evaporate more quickly than less volatile ones [16]. Evaporation rate of oil is dependent on various factors [25] explained as follows:

- Oil Type

Light oil evaporates more rapidly than heavy oil.

- Temperature

Higher temperatures increase the rate of evaporation.

- Wind Force

Oil evaporates more rapidly with increasing wind speed.

- Surface Area

The greater the area the more rapid the evaporation.

Molecules of spilt oil dissipate at different rates and are transported and weakened by environmental impacts. Since the rate of spreading relies on the consistency of the oil, light oils dissipate more quickly due to both an expansion in exposed zone and their higher rate of lighter molecules.

Estimations of evaporation rates is basically necessary to determine the consistency level of oil and changes in oil properties with time. Such calculations are carried out with simple methods, mainly based on an analytical model proposed by Stiver and Mackay [29].
If a liquid of the vapour pressure $\mathrm{P}\left(\mathrm{P}_{\mathrm{a}}\right)$ is spilled over an area of a $\left(\mathrm{m}^{2}\right)$, the rate of evaporation is given as follows [29]:

$$
N=k_{a} P /(R T)
$$

where $\mathrm{N}$ is the molar flux ( $\mathrm{mol} / \mathrm{s}), \mathrm{k}_{\mathrm{a}}$ - the mass transfer coefficient under the prevailing wind conditions $(\mathrm{m} / \mathrm{s}), \mathrm{R}$ - the gas constant $\left[8.314 \mathrm{~Pa} \cdot \mathrm{m}^{3} /(\mathrm{mol} . \mathrm{K})\right]$, and $\mathrm{T}$ - the environmental temperature (K). Eq.1 can be arranged to give [10]:

$$
d F_{v} / d t=k_{a} P_{v} /\left(V_{o} R T\right)
$$

where $\mathrm{F}_{\mathrm{v}}$ is the volume fraction evaporated, $\mathrm{t}$ - time $(\mathrm{s}), \mathrm{v}$ - the liquid's molar volume $\left(\mathrm{m}^{3} / \mathrm{mol}\right)$, and $\mathrm{V}_{\mathrm{o}-}$ the initial volume of spilt liquid $\left(\mathrm{m}^{3}\right)$. Its rearranging gives [16]:

$$
d F_{V}=\left[P_{V} /(R T)\right]\left(k_{a} d t / V_{o}\right)
$$

or

$$
d F_{v}=H \cdot d \theta
$$

The right side of Eq. 4 has been split into two dimensionless groups. The group " $\mathrm{k}_{\mathrm{a}} \mathrm{t} / \mathrm{V}_{\mathrm{o}}$ " is termed the "evaporative exposure" and is denoted " $\theta$ ". The evaporative exposure is a function of time, the spill area and volume (or thickness), and the mass transfer coefficient (dependent on the wind speed). The evaporative exposure can be viewed as the ratio of exposed vapour volume and initial liquid volume [10].

The group $\mathrm{P}_{\mathrm{v}} /(\mathrm{RT})$ or $\mathrm{H}$ is a dimensionless Henry's law constant or the ratio of the equilibrium concentration of the substance in the vapor phase, $\mathrm{P} /(\mathrm{RT})$, and that in the liquid $(\mathrm{l} / \mathrm{v})$. It is a function of temperature but not of other environmental conditions [10].

The product $\mathrm{H} \theta$ is thus the ratio of the amount which has evaporated and the amount originally present. If the liquid is pure, $\mathrm{H}$ is independent of $\mathrm{F}_{\mathrm{v}}$ and Eq. 6 can be integrated directly to give [29] :

$$
H \theta
$$

If $\mathrm{k}_{\mathrm{a}}$ and temperature are constant, the evaporation rate is constant and evaporation is complete ( $F_{V}$ is unity) when $\theta$ achieves the value of $1 / \mathrm{H}$. If the liquid is a mixture, $\mathrm{H}$ depends on $\mathrm{F}_{\mathrm{v}}$ and Eq. 5 can be integrated only if $\mathrm{H}$ is expressed in function of $F_{v}$, i.e. the principal variable of vapour pressure is expressed in function of composition.

The evaporation rate decreases in the course of time. If the liquid is pure, the resistance to mass transfer must lie entirely in the air phase because there is no necessity for the substance to diffuse in the liquid phase to the interface. The mass transfer coefficient $\mathrm{k}$ is then entirely an air-phase resistance term. If the liquid is a mixture it is possible that there is a contributing liquid-phase resistance, especially if 
the substance has a high air-liquid partition coefficient or if the liquid is viscous. The second approach is to use a gas stripping technique with an exit gas rate $G\left(\mathrm{~m}^{3} / \mathrm{s}\right)$. If the exit gas is saturated, the evaporation rate will be GP/(RT) (mol) as follows [11] :

$$
d F_{V} / d t=[G P /(R T)]\left(V / V_{o}\right)
$$

or

$$
d F_{V}=H \cdot d \theta
$$

The evaporative exposure $\theta$ is defined as $\mathrm{Gt} / \mathrm{V}_{\mathrm{o}}$ and is the actual ratio of vapour volume and liquid volume. The identical nature of Eq.4 and Eq.7 suggests that if surface (tray) and stripping experimental data are plotted in the form of $F_{v}$ versus $\theta$, the points should lie on a common line, $\theta$ being defined either as $\mathrm{k}_{\mathrm{a}} \mathrm{t} / \mathrm{V}_{\mathrm{o}}$ or $\mathrm{Gt} / \mathrm{V}_{0}[29]$.

\section{NATURAL DISPERSION}

Natural dispersion is the breaking of oil into small pieces due to motion of waves. This process has direct effect on the expansion of surface area which causes acceleration of biodegradation process [2]. The scattering rate is directly related to thickness of oil layer, surface tension, persistency, and environmental factors such as temperature, wavelength, wind speed etc [23].

The majority of oil spill modelling software used in industry utilize empirical expression proposed by Delvigne and Sweeney [4] to calculate dispersion rates. The relationship is mainly characterized by its dependence on the oil type, the energy of breaking waves lost in turbulence, and the fraction of sea surface covered by whitecaps, per unit time; the latter quantities are estimated empirically [23].

$$
F_{w C}=C_{b}\left(U_{w}-U_{w i}\right) / T_{w}
$$

Where the local wind speed $U_{w}$ is measured at the height of $10 \mathrm{~m}$ above $\mathrm{MWL}, \mathrm{U}_{\mathrm{wi}}$ represents a wind speed necessary for the "initiation" of breaking $\left(\approx 5 \mathrm{~ms}^{-1}\right), \mathrm{T}_{\mathrm{w}}$ is a characteristic wave period, and $\mathrm{C}_{\mathrm{b}}\left(\approx 0.032 \mathrm{sm}^{-1}\right)$ is a constant; A semi-emperical relation for the energy dissipation per unit surface area in a breaking event is given by:

$$
D_{b a} \approx 0.0034 p_{w} g H^{2} r m s
$$

Where $\mathrm{H}_{\mathrm{rms}}$ represents root mean square ( $\mathrm{rms}$ ) value of the wave height in the wave field, $(\mathrm{m}), \mathrm{p}_{\mathrm{w}}$ is water density $\left(\mathrm{kg} / \mathrm{m}^{3}\right)$ and $g$ represents gravity acceleration $\left(\mathrm{m} / \mathrm{s}^{2}\right)$ [5].

\section{MATERIALS AND METHOD}

In this study, two numerical modelling software systems were utilized to calculate and predict fate and trajectory of spilt oil in marine environment. For the calculation and simulation of weathering processes of oil the OILMAP and ADIOS software systems were selected for simulation.

OILMAP consisting a number of modules which can assist in planning, emergency decision making and case prosecution, is a PC - based spill model and response system created by Applied Sciences Associates (ASA). This software is being utilized globally since the mid-1990s by oil companies, academic institutions and research centres [28]. The simulation results obtained from OILMAP have been validated and approved at international level $[18,26]$. The reliability and performance level of OILMAP was found quite satisfactory based on field observations and hind-casting past hydrocarbon spills such as Persian Gulf War spill and Braer spills [27]. This oil spill software is considered the industry standard for use and complies with the ASTM Standard F2067-07 "Standard Practice for Development and Use of Oil Spill Models" [26, 17]. It was also used to calculate and simulate oil spill weathering processes of some global disasters such as Amoco Cadiz, Ixtoc and Persian Gulf War spills [18].

The system consists of single trajectory model for weathering process and stochastic model for contingency planning [11]. The model uses the specific properties of each oil type, including density, viscosity and surface tension to predict weathering processes such as spreading, evaporation, entrainment, and shoreline interactions [13]. The codes of software are available for different water areas such as open sea, near shore waters, semi-confined coastal waters, estuaries, rivers, lakes, and reservoirs [19].

The other model, ADIOS, is commonly used as an extensive oil products library containing more than a thousand crude oils and refined products [22]. It is also used as a reference weathering model, being compared with other new models, when ground-truth weathering data is not available. This software is developed by Lehr et al. [19] using the evaporative algorithm developed by Stiver and Mackay [29]. However, ADIOS does not simulate oil spill trajectory [8] and initiates the formation of a water-in-oil emulsion in their computer models until a specified percent evaporation for the crude oil has occurred. ADIOS can simulate oil transport and fate for water surface only. In this study the model was used for calculations of natural dispersion and evaporation. The 
simulation capabilities of each software system are shown in Tab. 1.

Tab.1. Simulation capabilities of selected models

\begin{tabular}{|l|c|c|}
\hline & ADIOS & OILMAP \\
\hline Advection & - & + \\
\hline Diffusion & - & + \\
\hline Wind Drift & - & + \\
\hline Stokes Drift & - & - \\
\hline Floating Objects & - & + \\
\hline Backtracking & - & + \\
\hline Stranding & + & + \\
\hline Spreading & + & + \\
\hline Evaporation & + & + \\
\hline Emulsification & + & + \\
\hline Natural Dispersion & + & + \\
\hline Vertical Movement & - & + \\
\hline Dissolution & - & + \\
\hline Sedimentation & - & - \\
\hline
\end{tabular}

Source: [8]

\section{STUDY SITE AND EXPERIMENTAL DESIGN}

Bay of Samsun located in southern part of Black Sea, with a diverse ecosystem, is selected to be model area in the study. The environmental sensitivity map with indicated spill point is shown in Fig.1.

It is clearly seen from the figure that the coasts have different levels of environmental sensitivity. For example Nature Parks are the habitat for over 320 species of birds. The shorelines of the Bay of Samsun concentrate migratory shorebirds and migrant land birds. Also some animals in danger of extinction such as ruddy ducks and sturgeon fish live in this area [20].

The Nature Parks contain different types of natural areas such as delta marshes, cultivated areas and fish stocks. The areas have the second priority of wildlife protection areas. There are two fishing ports located near the spill point. The anchovy fish is the mainstay of fisher folk. The fish stocks and fishing activities are expected to be badly affected in case of oil spill. These areas have the second priority of protection. There are some recreational areas including parks, cafeterias and living spaces considered risky areas. Summer resorts and beaches are located along the northwest coast of the Bay of Samsun [20].

Heavy industry has an accelerating development to satisfy the needs of population of the region in the last decade, and many industry branches have increased their capacities which

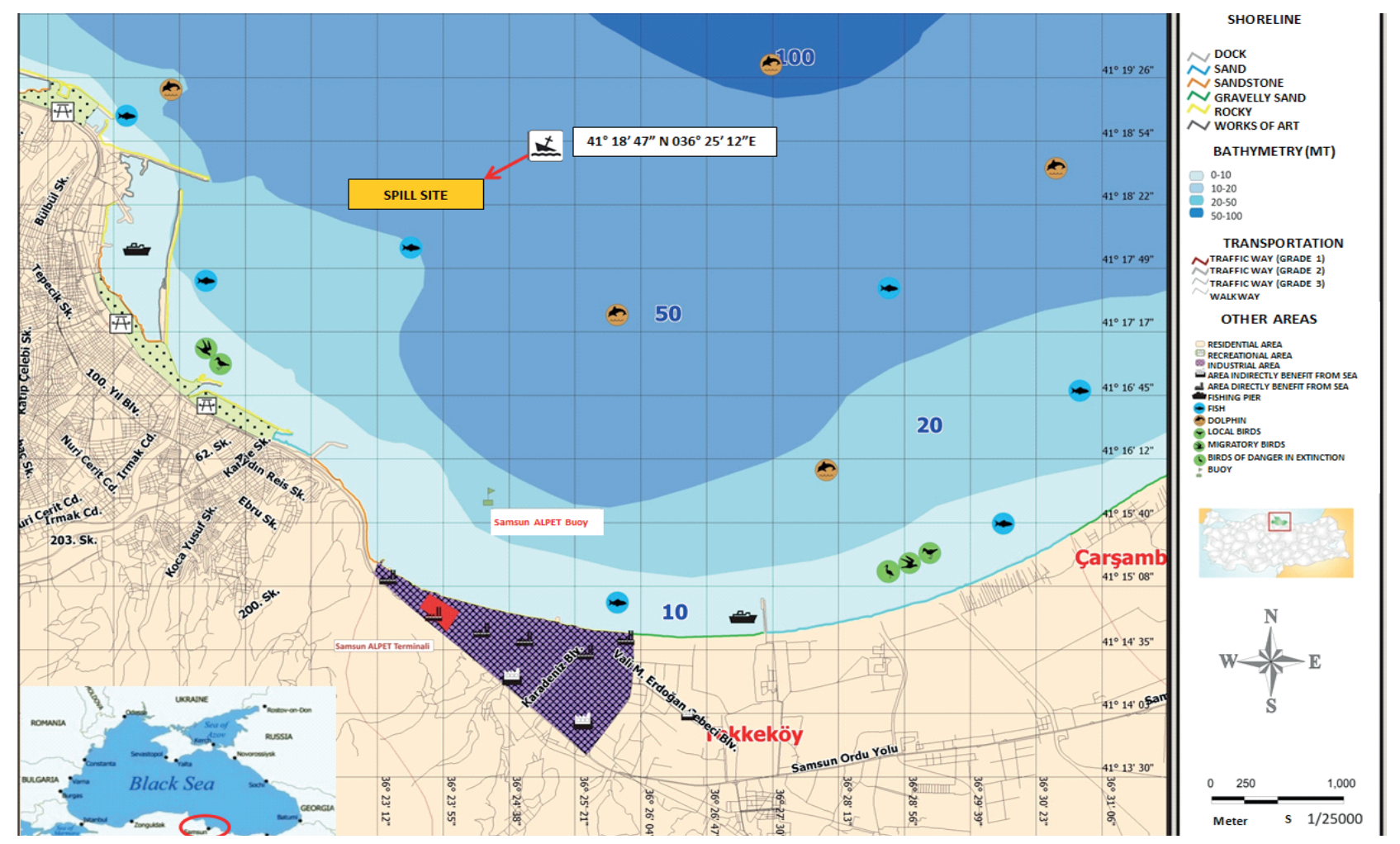

Fig. 1. Study area map: Environmental sensitivity map of Bay of Samsun, Turkey. Source: Adopted from [20] 
have led to an increase in marine transportation. Density of Black Sea shipping traffic is shown in Fig 2.

Note. The color coding represents traffic density in each area. The numbers refer to quantity of distinct vessels on a daily basis and count their positions per square $\mathrm{km}$. The colours stand for : blue - less than 30 ; green - 30 to 70 ; yellow - 71 to 140 ; red - more than 140 .

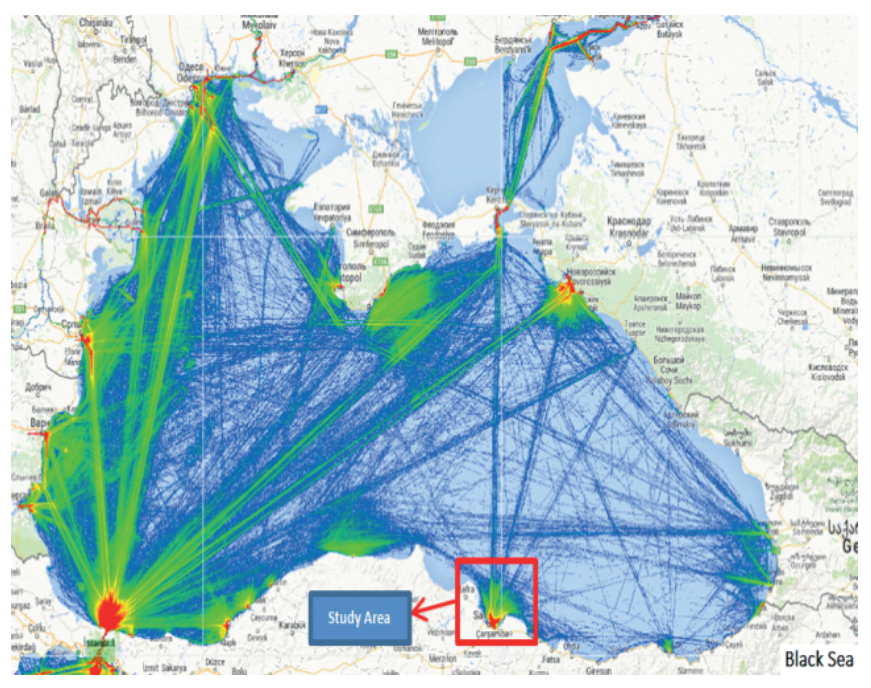

Fig 2. Black Sea shipping traffic density map (2000-2015) Source: [21]

There are 16 commercial ports operating in the region. Port of Samsun in which specific kind of cargo is handled has become the major gateway for the industrial zone. Main import products are coal, scrap, grain, wood and oil [3]. Oil terminals are also located in the region. Petrol Office, Total Oil, Alpet, Aygaz, Akpet and Milangaz are the main terminals in which oil and other harmful substances are handled. The main cargoes handled in the terminals are LPG, petrol, fuel oil and diesel oil.

The area is considered risky for some reasons. Black Sea trade is characterized by "the use of aged, smaller vessels, working well beyond their economic life and moving low value goods" [14]. The vessel accident reports indicate that losses of ships and other accidents mostly occur in certain regions such as Black Sea, which has the second greatest proportion (13\%) in terms of loss concentration just after Far East (17\%), The cited report has shown that vessels of age over 20 years often start a geographical move east when they are no longer able to be registered by better known classification institutions. In Fig. 3 oil spill density in Black Sea is shown.

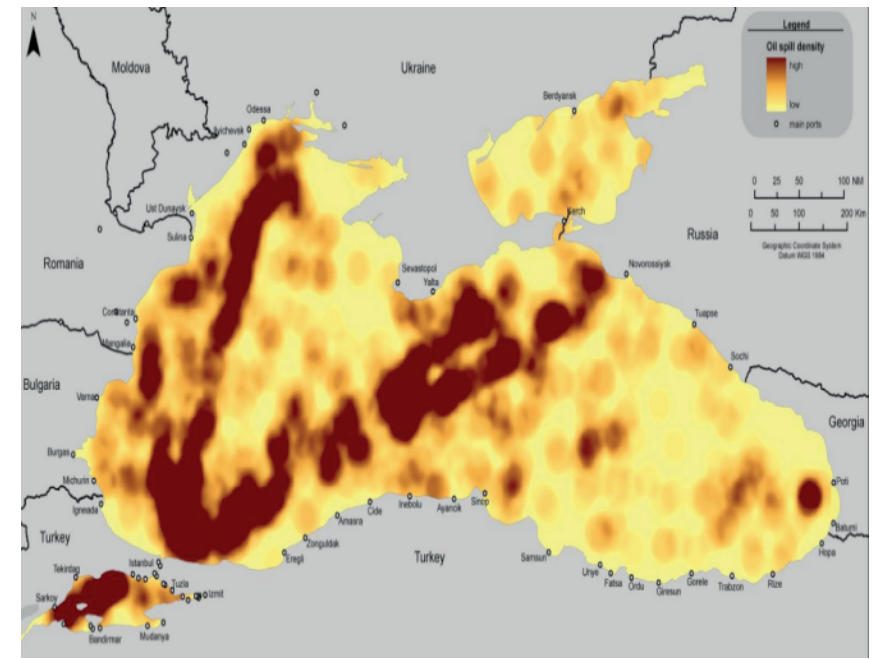

Fig. 3. Oil spill normalized density (2000-2004) Source: [9]

Note. The oil spill density has been spatially normalized to the spill widths [ = extent, size ?]. The darker areas signify the high anomaly regions.

The oil spill risks for the area were identified by applying Monte Carlo simulation, which allows to identify probability of spillage. The simulation results indicate that there are three main risks which may cause oil pollution in the area. The details of the simulation are shown in Tab. 2.

Tab. 2. Risk analysis results

\begin{tabular}{|c|c|c|c|c|c|}
\hline $\begin{array}{c}\text { Accident } \\
\text { Type }\end{array}$ & $\begin{array}{c}\text { Spill } \\
\text { Quantity } \\
\left(\mathbf{a v g} / \mathbf{m}^{3}\right)\end{array}$ & $\begin{array}{c}\text { Number of } \\
\text { Ships } \\
(\mathbf{A})\end{array}$ & $\begin{array}{c}\text { Spill Area/ } \\
\text { Area of } \\
\text { Samsun Bay } \\
(\mathbf{B})\end{array}$ & $\begin{array}{c}\text { Spill } \\
\text { Probability } \\
(\mathbf{C})\end{array}$ & $\begin{array}{c}\text { Accident } \\
\text { Probability } \\
(\mathbf{A x B x C})\end{array}$ \\
\hline Collision & 500 & 54 & $1 / 9$ & 0.101 & $6.06 \times 10^{-3}$ \\
\hline Grounding & 370 & 54 & $1 / 9$ & 0.07 & $4.2 \times 10^{-3}$ \\
\hline Sinking & 200 & 54 & $1 / 9$ & 0.193 & $1.16 \times 10^{-2}$ \\
\hline
\end{tabular}

Source: Adopted from [21]

From Tab. 2 it can be clearly concluded that there are three main accident risks which may cause oil spill in the area. This reveals that value of probability of vessel sinking is higher than for other accidents. The average spill quantities show that the greater value of cargo is spilt in case of collision.

\section{POLLUTANTS}

In this study three types of pollutants of different physical characteristics were selected. The pollutants have various weathering characteristics while spilled onto water. So the risks may vary as a result of different physical and chemical properties. The main weathering process determinants are of a wide range and strong relationship to each other. The table for comparing specifications of pollutants is shown below. 
Tab. 4. Comparison of specifications of pollutants

\begin{tabular}{|l|c|c|c|c|}
\hline & Units & Crude Oil & Diesel Oil & Fuel Oil \\
\hline Density at $15{ }^{\circ} \mathrm{C}$ & $\mathrm{kg} / \mathrm{m}^{3}$ & 889.0 & 852.0 & 975.0 \\
\hline Pour point & ${ }^{\circ} \mathrm{C}$ & -18 & -15 & 30 \\
\hline Flash Point & ${ }^{\circ} \mathrm{C}$ & 20 & 52 & 60 \\
\hline Viscosity at $50{ }^{\circ} \mathrm{C}$ & $\mathrm{mm}^{2} / \mathrm{s}$ & 10.2 & 2.9 & 80 \\
\hline $\mathrm{H}_{2} \mathrm{~S}$ Content & $\%$ & 1.1 & 2.0 & 0.5 \\
\hline
\end{tabular}

\section{ENVIRONMENTAL DATA}

The regional environmental data are obtained from long-term observation statistics which has been prepared by State Meteorological Institution. The main environmental determinants (temperature, winds and sea currents) of great effects on weathering processes, have been considered in the study. The speed and direction of the regional winds are identified in accordance with the frequencies of SSW (towards) direction with $2.9 \mathrm{~m} / \mathrm{s}$ average yearly speed. Local sea currents which have been generated by the coastal wave motion and wind force are also calculated as acting from north with $0.05 \mathrm{~m} / \mathrm{s}$ speed for the spill area. Water temperature has been considered to be $15^{\circ} \mathrm{C}$ which is the average yearly temperature.

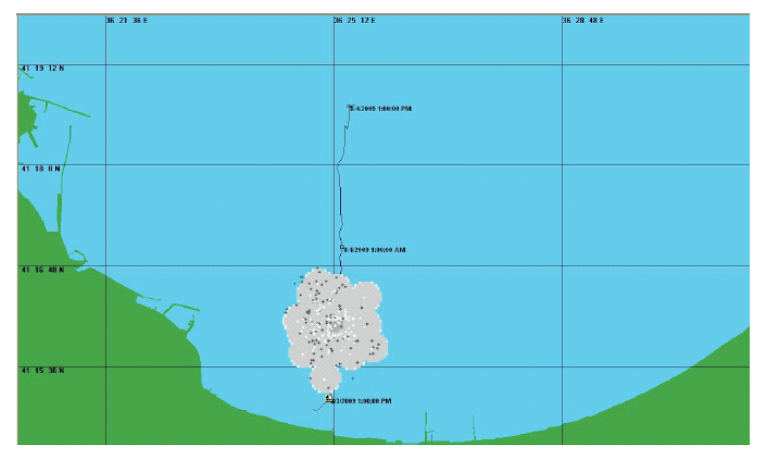

Fig.4(a). Scenario 1a (F/O - fuel oil spill of $\left.125 \mathrm{~m}^{3}\right)$

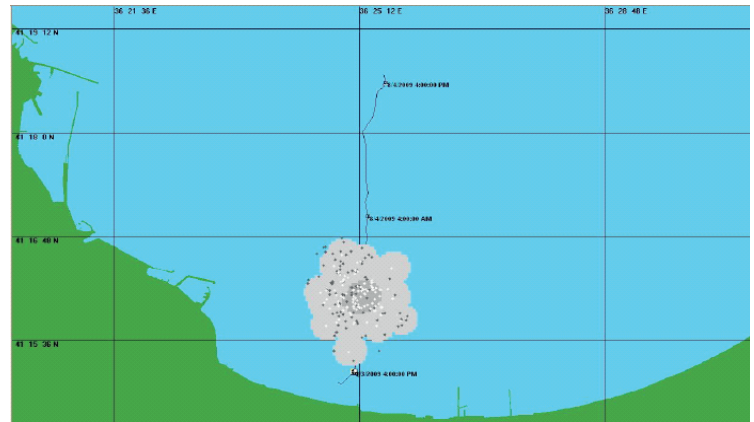

Fig. 4(b). Scenario $1 b\left(\mathrm{~F} / \mathrm{O} 250 \mathrm{~m}^{3}\right)$

\section{SCENARIOS AND MODEL}

Three scenarios have been identified and used in the model as shown in Tab. 5 .

Tab. 5. Summary of scenarios with spill information

\begin{tabular}{|c|c|c|c|}
\hline Scenario & Oil Type & Amount $\left(\mathbf{m}^{3}\right)$ & Model Run Period (h) \\
\hline 1a & \multirow{3}{*}{$\begin{array}{l}\text { FUEL OIL } \\
\qquad(\mathrm{F} / \mathrm{O})\end{array}$} & 125 & 24 \\
\hline $1 b$ & & 250 & 24 \\
\hline $1 c$ & & 500 & 24 \\
\hline $2 \mathrm{a}$ & \multirow{3}{*}{$\begin{array}{l}\text { DIESEL OIL } \\
(\mathrm{D} / \mathrm{O})\end{array}$} & 40 & 24 \\
\hline $2 b$ & & 80 & 24 \\
\hline $2 c$ & & 160 & 24 \\
\hline $3 a$ & \multirow{2}{*}{$\begin{array}{l}\text { CRUDE OIL } \\
\qquad(\mathrm{C} / \mathrm{O})\end{array}$} & 125 & 24 \\
\hline $3 b$ & & 500 & 24 \\
\hline
\end{tabular}

As indicated in Tab. 5, each scenario is divided into three sub-scenarios regarding the spill amount. The scenarios run with hourly period using particular environmental data and spill amount. Every spill scenario starts from the geographical position of $36^{\circ} 26^{\prime} 41^{\prime \prime} \mathrm{E} / 41^{\circ} 15^{\prime} 26^{\prime \prime} \mathrm{N}$. The model has run basing on the actual hourly weather data.

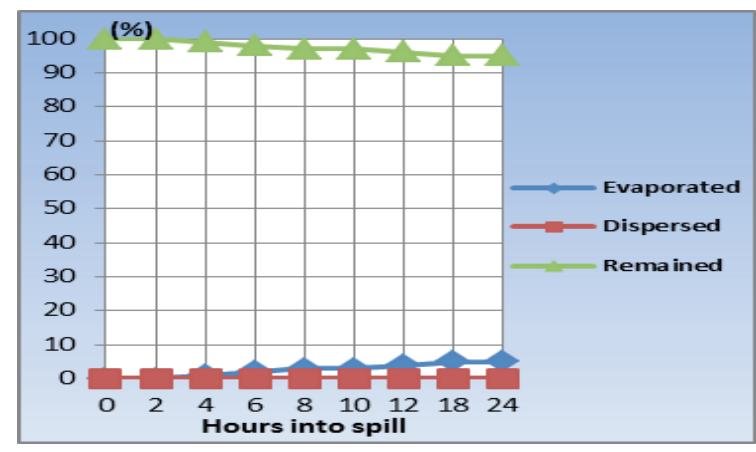

Fig. 5(a). F/O degradation chart (s/1a)

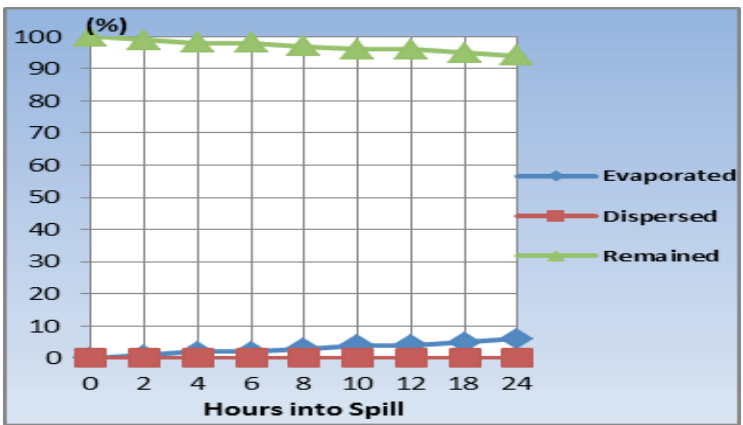

Fig. 5(b). F/O degradation chart (s/1b) 


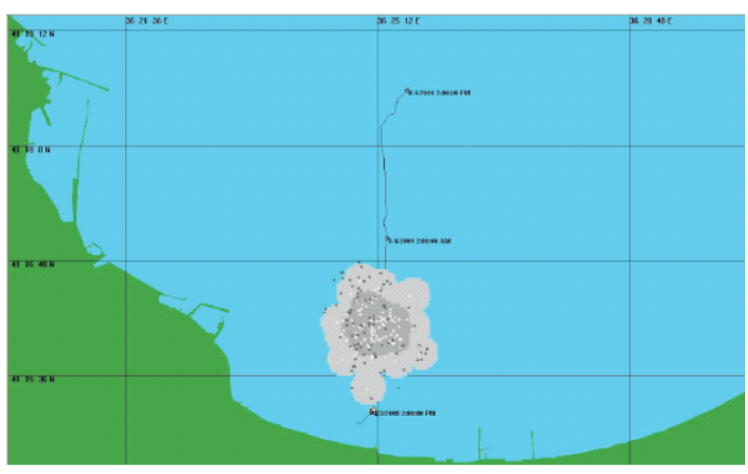

Fig.4(c). Scenario 1c (F/O 500m $\left.{ }^{3}\right)$

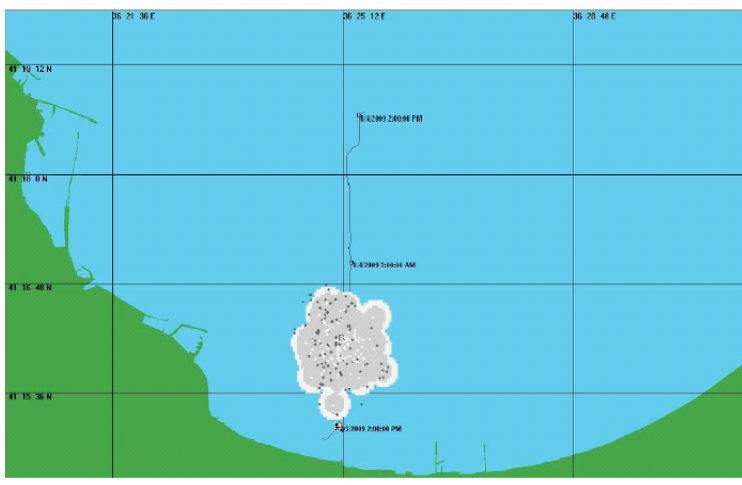

Fig.4(d). Scenario $2 a\left(D / O\right.$ - diesel oil spill of $\left.40 m^{3}\right)$

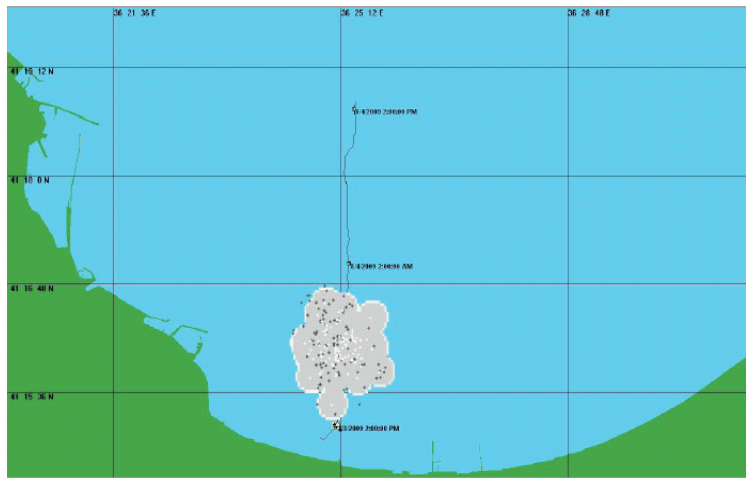

Fig.4(e). Scenario $2 b\left(\mathrm{D} / \mathrm{O} 80 \mathrm{~m}^{3}\right)$

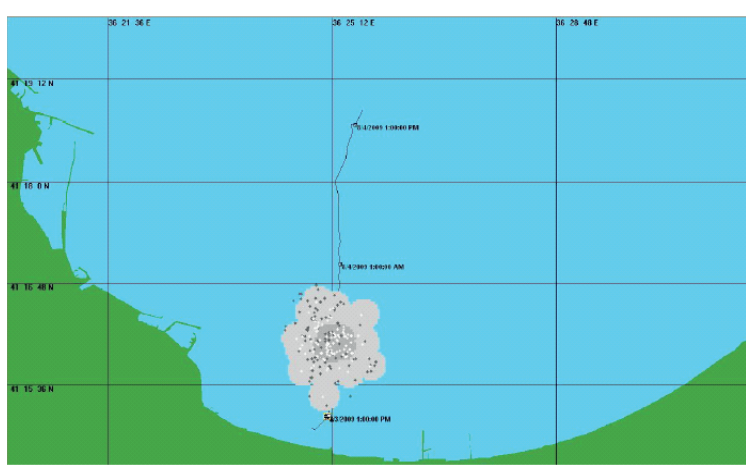

Fig.4(f). Scenario $2 c\left(D / O 160 \mathrm{~m}^{3}\right)$

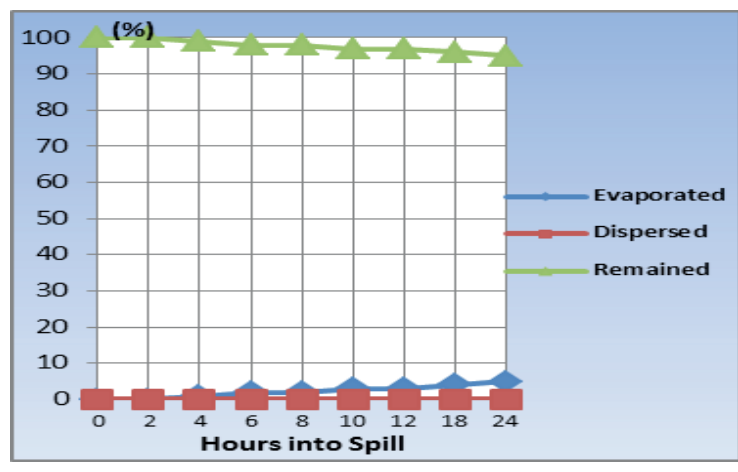

Fig. 5(c). F/O degradation chart (s/1c)

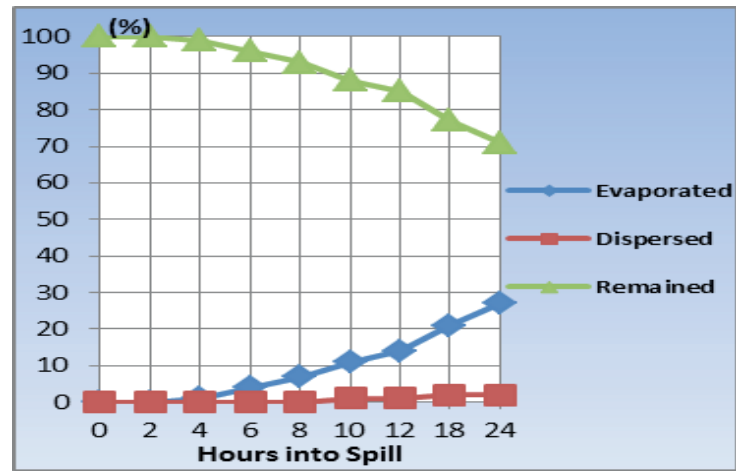

Fig. 5(d). D/O degradation chart $(s / 2 a)$

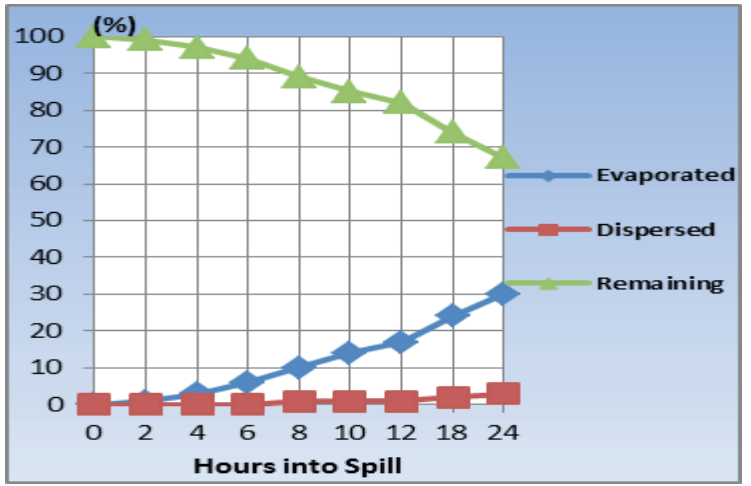

Fig. 5(e). D/O degradation chart $(s / 2 b)$

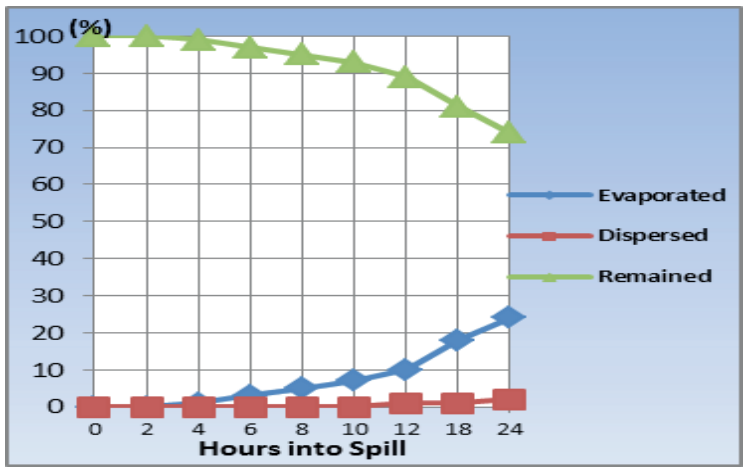

Fig. 5(f). D/O degradation chart $(s / 2 c)$ 


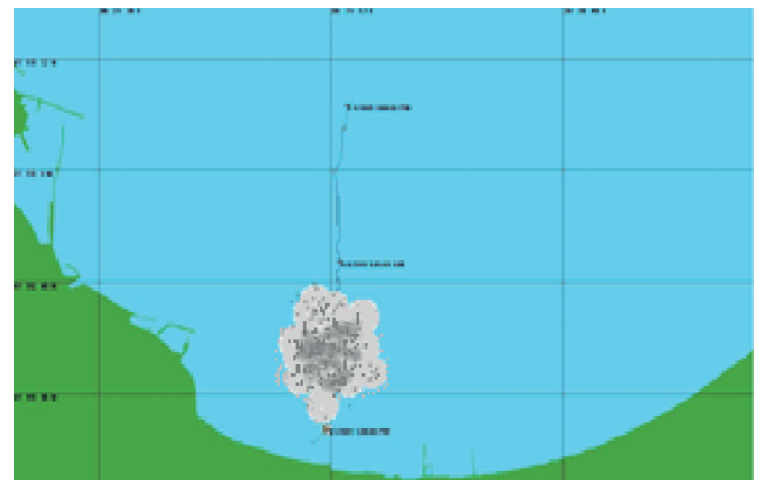

Fig.4(g). Scenario $3 a\left(C / O 500 m^{3}\right)$

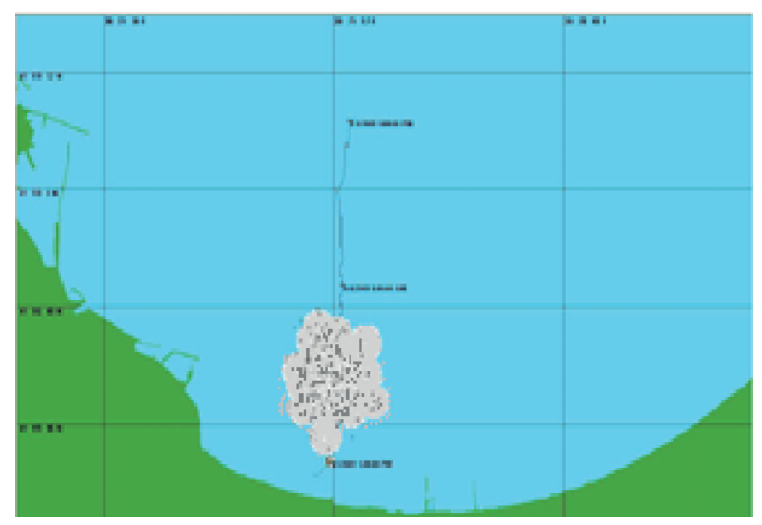

Fig. 4(h). Scenario 3c (C/O 125 m³)

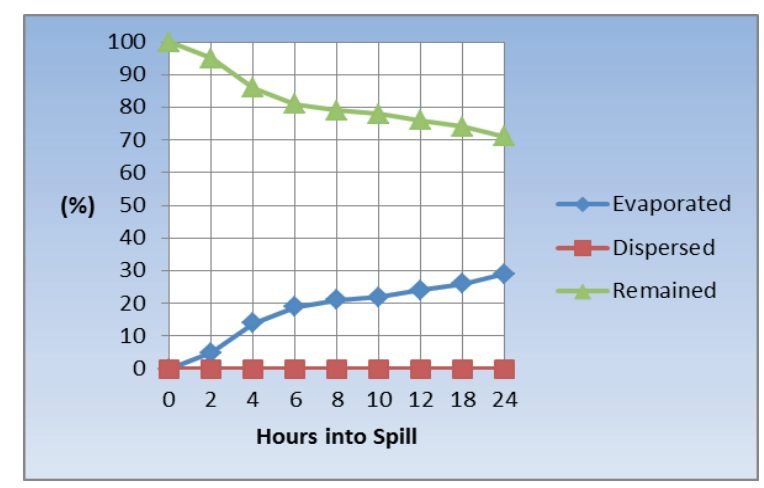

Fig.5(g). C/O degradation chart (s/3a)

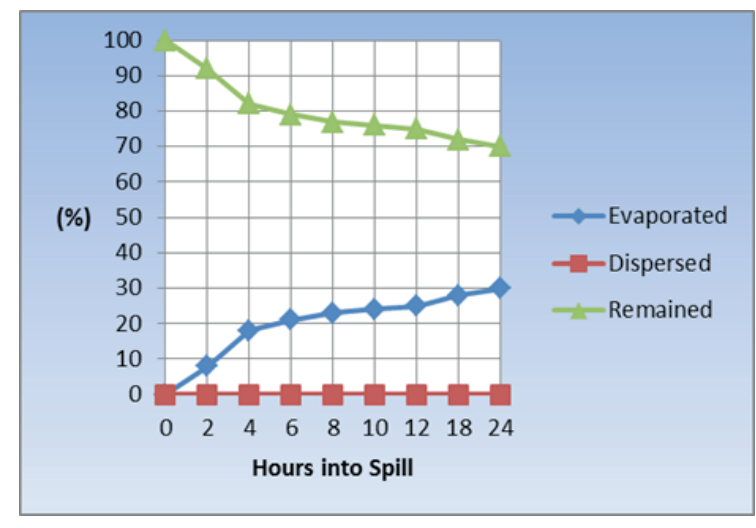

Fig.5(h). C/O degradation chart $(s / 3 b)$

\section{RESULTS}

The printouts of each scenario show that the movement of spill was mostly affected by sea currents and surface wind forces. The main weathering processes (evaporation, spreading, dispersion) are directly affected by environmental factors. Degradation of oil starts instantly when spilt onto water. The tracking of spill shows that the affected area is the same for all scenarios. As fuel oil is more viscose its floating part is greater than evaporation and dispersion. Diesel oil is more likely to disperse than float which constitutes more risks for benthic organisms. The evaporation process of crude oil starts earlier than that of diesel oil. Finally evaporation rates are quite close to each other. The spread velocity of fuel oil is lower than that of the other pollutants, owing to that response teams gain time to mobilize.

The study shows that the affected area and density of contamination have a strong relationship with the amount of pollutants. Spill area reaches $4 \mathrm{~km}^{2}$ for fuel oil spill, 4.5 $\mathrm{km}^{2}$ for diesel oil spill and $5.3 \mathrm{~km}^{2}$ for crude oil spill after $6 \mathrm{~h}$ period. The results indicate that refined substances are more resistant to spreading than crude ones. The different types of coast structure reveal that vulnerability to oil spill and finally generated wastage is changing.

According to the simulation, it is clear that fishing ports and Nature Park are under the risk of contamination for all scenarios. For this reason response operations team has to be mobilized at this area. In the below given Fig. 4 presenting weathering process fuel oil spill is shown with grey colour; diesel oil spill - with light grey and crude oil - with dark grey. This colouring represents contamination density. Estimated beaching time is calculated for $9 \mathrm{~h}$ after spill.

The figures present time dependent weathering process of each pollutant with different amount.

According to the illustrations concerning the first scenarios, only $6 \%$ of fuel oil (Fig.5a), 30\% of diesel oil (Fig.5d) and $32 \%$ of crude oil (Fig.5h) are evaporated after $24 \mathrm{~h}$. Diesel oil needs approximately $18 \mathrm{~h}$ to evaporate one quarter of total amount. Crude oil evaporation rates reach such values in shorter period. However fuel oil survives for longer period due to strong cohesive force and high viscosity. After $6 \mathrm{~h}$ period, only $2 \%$ of fuel oil is evaporated and $98 \%$ remains on water but diesel oil is degraded faster with $8 \%$ evaporation and $1 \%$ natural dispersion rates. Crude oil evaporates only with the rate of $22 \%$ within this period. Finally, $91 \%$ of diesel oil, $78 \%$ of crude oil and $98 \%$ of fuel oil remained on water after $6 \mathrm{~h}$ period. After $9 \mathrm{~h}$ period, beaching amounts are calculated equal to $120 \mathrm{~m}^{3}(96 \%)$ for fuel oil, 34 $\mathrm{m}^{3}$ (85\%) for diesel oil and $90 \mathrm{~m}^{3}$ (75\%) for crude oil.

According to the degradation processes concerning the second scenarios, only $5 \%$ of fuel oil (Fig.5b) and $27 \%$ of diesel oil (Fig.5e) are evaporated after 24 h. After $6 \mathrm{~h}$ period, only $2 \%$ of fuel oil evaporated and $98 \%$ remains on water. Although $4 \%$ of diesel oil is evaporated in this period but no 
dispersion was observed. After $9 \mathrm{~h}$ period, beaching amounts are calculated equal to $242.5 \mathrm{~m} 3$ (97\%) for fuel oil , $70.4 \mathrm{~m} 3$ (88\%) for diesel oil and $90 \mathrm{~m} 3$ (75\%) for crude oil.

The figures regarding to the third scenarios indicate that after $6 \mathrm{~h}$ period, only $2 \%$ of fuel oil (Fig. $5 \mathrm{c}$ ), $3 \%$ of diesel oil (Fig.5f) and 19\% of crude oil (Fig.5h) evaporated. After 24 h period, $5 \%$ of fuel oil, $24 \%$ of diesel oil and $29 \%$ of crude oil evaporated. In this period, only $2 \%$ of diesel oil has been naturally dispersed and no dispersion was observed for the other substances. After $9 \mathrm{~h}$ beaching quantities are calculated equal to $485 \mathrm{~m}^{3}$ (97\%) for fuel oil, 355 (71\%) and $108 \mathrm{~m}^{3}(93 \%)$ for diesel oil.

\section{CONCLUSION AND DISCUSSION}

In this study an oil spill trajectory released around Bay of Samsun was investigated and the trajectory of future accidents was predicted. Although many studies on oil spilling models were reported in literature, only a few of them dealt with Black Sea region which has closed sea conditions. The spilt oil badly affects the closed sea area due to the fact that there is no way for the spilt oil to escape so as to stop damaging effects to environment.

Two trajectory models were applied in this study. OILMAP, which was used to simulate trajectory of oil spill, is considered as a valid and reliable model by oil spill science and related industry circles. The simulation results can be considered highly satisfactory because this simulation model applied also in the past to simulate oil spill weathering process of global disasters meets the requirements of international standards (ASTM Standard F2067-07).

Another one, ADIOS, is also used as a reference weathering model. The software was also applied to simulate weathering processes of real spills. However, ADIOS does not simulate oil spill trajectory and initiate the formation of a water-inoil emulsion until after a specified percent evaporation of crude oil has occurred. ADIOS can simulate oil transport and fate only for water surface. Codes of the software system are available for different water areas such as open sea, near shore waters, semi-confined coastal waters, estuaries, rivers, lakes, and reservoirs.

Although the models in question are supported by oil spill science and industry circles, the results can be used only to assist in making better decisions.

Within this scope it was clearly identified that environmental factors (winds, currents, temperature etc.) and pollutant characteristics (viscosity, boiling point, specific gravity etc) are the main determinants of weathering process. The results revealed that in case of oil spills, with average environmental conditions, there is a risk of contamination for the city of Samsun. Although the area under the risk is the same, contamination density is totally different depending upon the quantity and the type of spilt oil.

Beaching amount of fuel oil is higher than that for other substances; so, their negative impact on environment is quite different. Not only beached quantity but also oil type is the main factor of contamination density which determines response strategy and cleaning operations. Basing on this study it was also concluded that the degradation life time is dependent on the oil type and viscosity.

One of the most important conclusions of the study is that increase in spilt oil quantity results in decrease of degradation rates. Besides, refined products such as fuel oil and diesel oil cannot degrade as easy as crude products. This study indicates that although specifications of crude oil are similar to diesel oil, their calculated weathering processes run differently.

The simulation results can be utilized for guidance purposes only. The characteristics and behaviour of oil spilt in an uncertain marine environment may differ slightly from those simulated. The results may be useful for many organizations related to oil spill response operations. The information can be also used to improve the emergency management systems in order to protect the human health, coastal management, and marine environment.

\section{LIMITATIONS OF THE STUDY}

- Oil spill science needs accurate and reliable data. Although the models used in this study are based on the available real data, their results present only predictions of an oil trajectory.

- In real environment, the oil spill trajectory is extremely complicated due to uncertainties of data such as spill location, oil type, environmental factors and oil spill response.

- The models are very sensitive to uncertainties of data, such as quantity of spilt oil and environmental conditions. Besides, results are dependent on the quality of the environmental parameters. Therefore the reliability of data providing services is so important for getting better solutions.

- The specifications of the oil contained in the models' library may not match those of the spilt product; however, additional oil trajectory analysis can be carried out.

\section{RECOMMENDATIONS FOR FURTHER RESEARCH}

- In the future similar studies should be conducted with different spill models in order to determine validation level of the research.

- This study is based on the scenarios derived from risk assessment studies concerning oil spill in Bay of Samsun. Other risk assessment methods can be used for better results. Besides, for real oil spill conditions dynamic data should be included to find instant and reliable solutions.

\section{ACKNOWLEDGEMENTS}

The author would like to thank Turkish State Meteorological Service and Seagull Oil Spill Response Ltd for their help in providing data and Dokuz Eylul University Maritime Faculty for their support to this project. 


\section{BIBLIOGRAPHY}

1. Ahlstrom S.W.: A mathematical model for predicting the transport of oil slicks in marine waters. Battelle Pacific Northwest Laboratories Richland, Wash, USA 1975.

2. Blaikley D.R., Dietzel G.F.L., Glass A.W., Van Kleef P.J.: Sliktrak-A computer simulation of offshore oil spills, cleanup, effects and associated costs. EPA/API Oil Spill Conference Proceedings, New Orleans, USA 1977, pp. 45-52.

3. Bloem, M.A., Putten M.A, Deveci A.,Tuna O.: Maritime Turkey: market research. Maritime By Holland, Netherland 2013.

4. Delvigne G.A.L., Sweeeney C.E.: Natural dispersion of oil. Oil \& Chemical Pollution 1988, Vol. 4, pp. 281-310.

5. Delvigne G.A.L.: Natural dispersion of oil by different sources of turbulence. International Oil Spill Conference Proceedings, California, USA 1993, pp.415-419.

6. Elliot A.J., Hurford N.: The influence of wind and wave shear on the spreading of a plume at sea. Oil and Chemical Pollution 1989, Vol.5, pp.347-363.

7. Fay J.A.: The spread of oil slicks on a calm sea. Fluid Mechanics Laboratory, Dept. of Mech. Eng., MIT, Cambridge, Mass. 1969.

8. Fernandes R., Neves R., Viegas C., Leitão P., Hidromod L.: Integration of an oil and inert spill model in a framework for risk management of spills at sea: a case study for the Atlantic area. In 36th AMOP Technical Seminar on Environmental Contamination and Response, Portugal 2013, pp. 4-6.

9. Ferraro G.: Monitoring sea-based oil pollution in the black sea: jrc activities?

10. Fingas M.: Modeling oil and petroleum evaporation. Journal of Petroleum Science Research 2013, Vol. 2, No: 3.

11. Fingas M.: Oil spill science and technology - prevention, response, and cleanup. Gulf Professional Publishing (Elsevier), Burlington, MA, USA 2011.

12. Fingas M.: Oil spill science and technology. Gulf Professional Publishing (Elsevier), Burlington, MA, USA 2016.

13. IMO (International Maritime Organization): Catalogue of computer programs and internet information related to responding to oil spills, London, UK 2000.
14. International Transport Workers' Federation (ITF): Unions slam 'sea of shame', [online]. Available: www. itfglobal.org /pressarea/ index.cfm/pressdetail/7543/region/1/section/0/ order/1[accessed 20th November 2012]

15. ITOPF (International Tanker Owners Federation): Fate of oil spills, London, UK 2002.

16. Jordan R.E., Payne J.R.: Fate and weathering of petroleum spills in the marine environment. Ann Arbor Science, Ann Arbor, MI, USA 1980.

17. King B., McAllister F., Hubbert G.: Data requirements for calibration and validation of the spill model OILMAP. In, Marine Meteorology and Related Oceanographic Activities. WMO Report No. 44. MARPOLSER 98 Proceedings 1999 Vol.1 Research Papers, WMO/TD - No. 959, pp. 35-52.

18. Kolluru V., Spaulding M.L., Anderson E.: A three dimensional subsurface oil dispersion model using a particle based technique. 17th Arctic and Marine Oil Spill Program, Technical Seminar, June 8-10, Vancouver, British Columbia, Canada 1994, pp. 767-784.

19. Lehr W., Jones R., Evans M., Simecek-Beatty D., Overstreet R.: Revisions of the ADIOS oil spill mode. Environmental Modeling \& Software 2002, Vol. 17 No. 2, pp.189-197.

20. MARSER (Seagull Oil Spill response Limited): Black Sea Oil spill response plan, Turkey 2015.

21. Mityagina M., Lavrova O.: Satellite survey of inner seas: oil pollution in the Black and Caspian seas. Remote Sens. 2016, Vol. 8, pp.875.

22. NOAA (National Oceanic and Atmospheric Administration): Automated data inquiry for oil spills, USA 2012.

23. Papadimitrakis I., Psaltaki M., Markatos N.: 3-D oil spill modeling: natural dispersion and the spreading of oil-water emulsions in the water column'. Global Nest Journal 2011, Vol.13 No. 4, pp. 325-338.

24. Soltanpour M., Wijayaratna N., Hajisalimi Z.: Numerical modeling of oil slick spread in the Persian Gulf. International Journal of Maritime Technology 2013, Vol.1 No.1, pp.57-66.

25. Speight J.G., Arjoon K.K.: Bioremediation of petroleum and petroleum products. Hoboken, Salem, Mass: John Wiley\&Sons, N.J, USA 2012.

26. Spaulding M.L., Howlett E., Anderson E., Jayko K.: OILMAP- A global approach to spill modeling. 15th Annual Arctic and marine Oilspill Program, Technical Seminar, Edmonton, Canada 1992. 
27. Spaulding M. L., Kolluru V. S., Anderson E., Howlett E.: Application of three dimensional oil spill model (WOSM/ OILMAP) to hindcast the Braer spill. Spill Science and Technology Bulletin 1994, Vol. 1, No: 1, pp. 23-35.

28. Spaulding M.L., Opishinski T., Anderson E., Howlett E., Mendelsohn D.: Application of OILMAP and SIMAP to predict the transport and fate of the North Cape spill. Narragansett, RI. 19th Arctic and Marine Oil Spill Program, Technical Seminar, June 12-14, Calgary, Alberta, Canada 1996, pp. 745-776.

29. Stiver W., Mackay D.: Evaporation rate of spills of hydrocarbons and petroleum mixtures. Environment Science and Technology 1984, Vol. 18, 834-840.

30. Zalewski P., Gucma L.: Damage probability of offshore pipelines due to anchoring ships. Polish Maritime Research 2003, Vol. 4, pp. 6-12. 